\title{
A RESPONSABILIDADE DO ADMINISTRADOR DE SOCIEDADE ANÔNIMA
}

\section{Márcia Andrade Santiago}

Mestranda em Direito Comercial na PUC/SP, Advogada.

\begin{abstract}
SUMÁRIO: Introdução; $1 \mathrm{O}$ administrador de empresas e seus deveres; $1.1 \mathrm{O}$ dever de diligência; $1.2 \mathrm{O}$ dever de observar a finalidade das atribuições; $1.3 \mathrm{O}$ dever de manter sigilo (insider trading); $1.4 \mathrm{O}$ dever de informação (full disclosure); $2 \mathrm{~A}$ responsabilidade civil do administrador na LSA; Conclusão; Referências bibliográficas.
\end{abstract}

RESUMO: O presente trabalho visa a retratar a responsabilidade patrimonial dos administradores das sociedades constituídas sob a forma de sociedade anônima, por ser ainda tema palpitante e dos mais fascinantes na seara do direito comercial. A abordagem se dá através da análise dos deveres imputados aos administradores, bem como se o descumprimento dos deveres que ensejaram a responsabilidade cuida das relações internas ou externas da sociedade. Isso porque o surgimento da responsabilidade patrimonial do administrador e o modo como surtirão efeitos diversos sofrerão alterações conforme se tratar de responsabilidade interna ou externa ao corpo social, e da necessidade de se traçar solução justa ao envolvimento pessoal dos administradores de sociedades para que não incorramos em ampliação tendenciosa e injusta que possa até mesmo coibir a vida empresarial.

PALAVRAS-CHAVES: responsabilidade, administrador.

ABSTRACT: The present article embraces the responsibility of the manager of the Stock Corporation, once it remains a pulsating and fascinating issue in Commercial Law. The approach is done through the analysis of the duties attributed to the managers, as well as if the disobedience of those duties is related to the internal or external affairs. The appearance of the patrimonial liability of the manager of the Stock Corporation and the form that will take effect suffers modifications accordingly to its nature, i.e. regarding internal or external affairs. Therefore, a necessity of constructing fair solutions to the personal involvement of the company managers exists, in order not to create a tendentious and unfair increase of the responsibility that may cohibit the enterprising achievements.

KEYWORDS: responsibility, management.

\section{INTRODUÇÃO}

A prática comercial existe desde a Antigüidade e adquiriu status jurídico com a ascensão da burguesia na Idade Média, e sua face societária liga-se ao próprio surgimento do capitalismo. Diante desse contexto, a evolução do direito societário nos indica a alteração das formas de associação de fins comerciais, que fugiram da responsabilidade dos sócios de forma ilimitada para uma responsabilidade limitada ao montante do capital investido, com a substituição progressiva das sociedades em nome coletivo pelas sociedades por cotas de responsabilidade limitada e sociedades por ações.

Por outro lado, ganhou fôlego a figura do gestor de sociedades, o moderno administrador de empresas, cujos atos, poderes e deveres ganham relevância ímpar no direito, especialmente com a evolução dos estudos sobre a responsabilidade civil que se espraia por todo o ordenamento jurídico. 
Para melhor situarmos a responsabilidade dos administradores sociais, faz-se imperioso que se delimite a extensão de seus poderes e deveres, porque é na extrapolação do primeiro e no descumprimento do segundo que surgirá o dever de reparar - a responsabilização.

Daí a responsabilidade patrimonial dos administradores consistir justamente na violação dos deveres, impostos por lei e pelos estatutos sociais, muitas vezes explícitos no texto legal, outras, expostos implicitamente através de princípios gerais, podendo com tais ações ou omissões causar lesão à sociedade, aos sócios e a terceiros.

\section{O ADMINISTRADOR DE EMPRESAS E SEUS DEVERES}

A atuação dos administradores de empresas, das sociedades anônimas fechadas ou abertas, vem ganhando terreno paralela e continuamente ao aumento de circulação de riquezas, cada vez mais adquirindo dinâmica própria ao cercar-se de novas técnicas de captação de clientela, circulação de moeda, novos meios de emissão de títulos, aliada ao desenvolvimento tecnológico e científico.

É nesse sentido que, mesmo nas empresas de menor porte, ainda aquelas de resistente constituição familiar, persiste cada vez mais a necessidade de profissionalização da gestão para que se mantenham a competitividade e o dinamismo de atuação no mercado, com a contratação de "executivos-máquina" que se encaixam na engrenagem produtiva como molas mestras de decisões múltiplas, compromissados com a multiplicação de riquezas - o lucro.

NELSON ABRÃO sintetiza a tendência acima ao concluir que "a profissionalização da empresa tem sido, na etapa de globalização da economia, forte fator de aperfeiçoamento, redução dos custos internos e dos conflitos na própria sociedade, de tal maneira que a atribuição da gerência a pessoa estranha ao corpo da sociedade não afigura medida excepcional, ou de terceirização da sua atividade, porém um instrumento que conserva os ingredientes de uma performance livre de eventuais obstáculos" (ABRÃO, 2000: 114).

É desse modo que os atos praticados por administradores de sociedades anônimas (diretores e conselheiros) assumem papel relevante de tal forma no mundo capitalista que, no tocante às companhias de capital aberto que operam no mercado de valores mobiliários, já é corrente a tutela de interesses difusos e coletivos para coibir práticas abusivas e que comprometem imediatamente a investidores diretos, bem como, mediatamente, à economia nacional.

Lastreados ainda nos ensinamentos do insigne comercialista NELSON ABRÃO, administrador é aquele que, ao dirigir a sociedade à realização do objeto a que ela se propõe, coloca em prática as medidas de caráter econômico-financeiro, de comando e representação (ABRÃO, 2000: 112).

Os administradores em uma sociedade anônima são os membros da diretoria e do conselho de administração, ambos com deveres e responsabilidades no desempenhar de suas funções conforme o prescrito no art. 138 e seguintes da Lei ${ }^{\circ} 6.404 / 76$, Lei das 
Sociedades Anônimas (LSA), sendo certo ainda que o leque de atribuições de um administrador ultrapassa os lindes legais, que nem sempre contemplam de modo explícito tais obrigações.

No entanto, firmemo-nos naqueles deveres fixados na LSA, que inerentes à administração conduzem à fiel perseguição dos objetivos sociais e que são condutas de valor dos administradores, como os deveres de diligência, lealdade, informação e sigilo, que geram responsabilidade civil e que serão a seguir esmiuçados.

\subsection{O dever de diligência}

$\mathrm{O}$ art. 153 da LSA determina que "O administrador da companhia deve empregar, no exercício de suas funções, o cuidado e diligência que todo homem ativo e probo costuma empregar na administração dos seus próprios negócios".

Tal definição legal prevê aos administradores que, no exercício da gestão empresarial, estes deverão aplicar critério e empenho, dedicando-se com cautela e probidade à consecução do objeto social e da função social da empresa, atendendo às normas estatutárias e legais como se estivesse gerindo negócio próprio. Esse conjunto de tarefas traduz-se na forma de diligência.

Para o jurista italiano MASSIMO BIANCA, a diligência é o empenho de energia e dos meios úteis para a realização de um determinado fim, e seus elementos informadores são a atenção, a cautela, a perícia e a legalidade da conduta, mencionando, ainda, que tais meios se traduzem na diligência aplicada pelo bom pai de família (BIANCA, 1990).

O uso da expressão bom pai de família encontra-se superado, aparecendo expressamente na legislação italiana que equipara a diligência do administrador à do mandatário, e, por conseguinte cuida também da diligência devida pelo bom pai de família. Para FRANCESCO GALGANO, é a diligência a ser aplicada nas obrigações de meio, uma diligência normal e ordinária, e não uma diligência especial, de maior ou de menor intensidade, entendimento também partilhado por alguns expoentes da doutrina comercial brasileira (GALGANO, 1988: 294).

FÁBIO ULHOA COELHO entende que devem ser aplicadas diretrizes da administração de empresas, que preconiza como diligente "o administrador que observa os postulados daquele corpo de conhecimentos tecnológicos, fazendo o que nele se recomenda e não fazendo o que se desaconselha", ou seja, empregando na condução dos negócios sociais as cautelas, métodos, recomendações, postulados e diretivas da arte de bem administrar, tendo em vista a realização dos fins da empresa, sendo este o meio de se tornar possível a prova da quebra de diligência, vez que assim é passível de perícia (COELHO, 2001: 242).

No entanto, foi JOSE MARIA GARRETA SUCH ${ }^{1}$ quem melhor definiu o dever de conduta diligente ao colocar que:

1 "El administrador debe actuar como actúa un ordenado empresario, es decir como una persona que no arriesga en operaciones descabelladas su próprio patrimonio, sino que mediante un adecuado cálculo 
"o administrador deve atuar como atua um empresário estruturado, é dizer como uma pessoa que não arrisca em operações descabidas seu próprio patrimônio, sendo que mediante um adequado cálculo de possibilidades atua em busca de um resultado previsível, não que deva atuar conservadoramente sem incorrer em risco algum, somente não pode fazê-lo com desprezo ao cálculo de probabilidades e de risco razoável" (tradução livre).

Ora, a diligência do administrador se afere por técnica e bom senso: a técnica, no que tange aos postulados administrativos e a obediência fiel às regras legais, especialmente nas tarefas cotidianas como aferição de resultados, demonstrações financeiras, pagamento de tributos, arquivamentos de documentos em órgãos públicos e tantos outros deveres de ordem burocrática; e bom senso, na medida em que nas transações comerciais são levados em conta múltiplos fatores de ordem econômica e que devem se coadunar com o objetivo social da empresa a fim de se obterem melhores resultados.

\subsection{O dever de observar a finalidade das atribuições}

A fiel observância da finalidade do cargo ocupado aliada à finalidade do objeto social da empresa é matéria ocupada pelo art. 154 da LSA que determina que o administrador deverá exercer as atribuições conferidas por lei e pelos estatutos sociais unicamente para lograr os fins e interesses da companhia, observando-se, ainda, as exigências do bem público e da função social da empresa.

A teoria do desvio ou abuso de poder, que tem suas origens no direito administrativo, perfeitamente se adapta ao direito societário, sendo que o administrador recairá nas hipóteses de abuso de poder, tanto no sentido de não-atendimento das finalidades do objeto social e demais obrigações constantes do Estatuto social e da lei, caracterizando desvio de finalidade, quanto no sentido de exceder os poderes e deveres ali contidos, ou seja, ultrapassando os limites do razoável na persecução da finalidade social ou legal.

Vale dizer, configurará abuso ou desvio de poder todas as vezes que o administrador incorrer em uma ou mais proibições constantes dos $\S \S 1^{\circ}$ ao $4^{\circ}$ do art. 154 da LSA, ou seja: a) privilegiar grupo ou classe de acionistas; b) praticar ato de liberalidade à custa da companhia; c) tomar por empréstimo recursos ou bens da companhia sem prévia autorização da assembléia-geral ou do conselho de administração; d) usar em proveito próprio ou de sociedade em que tenha interesse, ou de terceiros, os seus bens, serviços ou créditos; e) receber de terceiros, sem autorização estatutária ou da assembléia-geral, qualquer modalidade de vantagem pessoal, direta ou indireta, em razão do exercício de seu cargo.

de posibilidades actúa en busca de un resultado previsto; no es que deba actuar conservadoramente sin incurrir en riesgo alguno, sino que no puede hacerlo con desprecio del cálculo de probabilidades y del razonable riesgo." (SUCH, Jose Maria Garreta. La responsabilidade civil, fiscal y penal de los administradores de las sociedades, p. 77) 
A título exemplificativo de abuso de poder, JOSÉ WALDECY LUCENA identifica a sistemática de retenção de lucros, auto-atribuição de elevados honorários, outorga de vantagens pessoais a si próprio e a familiares, bem como o uso de veículos, viagens e a inclusão de empregados particulares na folha de pagamento da empresa (LUCENA, 1997: 341).

Daí, para fins de caracterização de desvio ou abuso de poder na seara da responsabilidade do administrador societário, bastará que este pratique quaisquer das condutas suso indicadas, isto é, sem respeito ao disposto no estatuto, ou no descaminho da norma legal e dos valores que estas inspiram.

\section{$1.3 \mathrm{O}$ dever de manter sigilo (insider trading)}

A teor do disposto no art. 155 da LSA, o dever de lealdade configura condutas proibidas aos administradores: a) usar, em benefício próprio ou de outrem, com ou sem prejuízo para a companhia, as oportunidades comerciais de que tenha conhecimento em razão do exercício de seu cargo; b) omitir-se no exercício ou proteção de direitos da companhia ou, visando à obtenção de vantagens, para si ou para outrem, deixar de aproveitar oportunidades de negócio de interesse da companhia; c) adquirir, para revender com lucro, bem ou direito que sabe necessário à companhia, ou que esta tencione adquirir; d) guardar sigilo sobre qualquer informação que ainda não tenha sido divulgada para conhecimento do mercado, obtida em razão do cargo e capaz de influir de modo ponderável na cotação de valores mobiliários, sendo-lhe vedado valerse da informação para obter, para si ou para outrem, vantagem mediante compra ou venda de valores mobiliários; e) negligenciar na função in vigilando aos seus subordinados e terceiros de sua confiança no tocante às questões da companhia.

Das proibições constantes da lei, é de se destacar o dever de sigilo acerca das operações e questões empresariais, que se estende à vigilância e cautela do administrador para com aqueles que lhe circundam e que também tenham acesso a tais informações. Ora, tal cuidado se justifica pelo velho ditado popular de que "o segredo é a alma do negócio", e, portanto, existem informações a respeito dos negócios da empresa, tais como valores, fórmulas, métodos produtivos e intenções de atuação, que se veiculadas abertamente poderiam comprometer o desempenho econômico da sociedade.

Vale dizer, no mais das vezes as questões afetas à empresa terão caráter confidencial, tanto é assim que é expediente comum o uso das cláusulas de confidencialidade ou até mesmo contratos de confidencialidade, abrangendo não só os administradores de alto escalão, mas também os funcionários de confiança destes, bem como os demais funcionários que se envolverão no negócio.

A esses atos de deslealdade a doutrina americana denominou insider trading cujo objetivo é coibir a utilização de informações privilegiadas e não divulgadas ao público com o intuito de obter vantagem para si ou para terceiros.

Ademais, o uso de informações privilegiadas também encerra em outra conduta faltosa do administrador, que, além do dever de manter sigilo sobre assuntos da companhia, não poderá se valer de tais informações para benefício próprio ou de 
terceiros, especialmente em questões que implicam seus interesses pessoais. Em tais casos, cabe ao administrador informar à sociedade da ocorrência de conflito de interesses, haja vista que a natureza humana nesses casos demonstra aptidão para favorecer a si mesmo, em detrimento de outros.

Assim, ao se declarar impedido de atuar em determinada questão social através da consignação em ata de reunião do conselho de administração ou de diretoria, deverá também explicar a natureza e extensão de seu interesse (art. 156, LSA). Assim, o administrador estará sendo leal não só aos seus interesses pessoais, mas também à companhia.

\subsection{O dever de informação (full disclosure)}

Por derradeiro, subsiste ao administrador o dever de informar previsto no art. 157 da LSA, que, ao contrário do que pode a nomenclatura sugerir, não confronta o preceito anterior relativo ao dever de sigilo.

Também oriundo do direito norte-americano, este subdivide-se em dois deveres: a) informação interna, aos acionistas da companhia, e b) a informação ao mercado, especialmente devidas pelas sociedades de forma aberta e que contenham títulos negociados em bolsa de valores e mercados de balcão organizado.

No entender de RUBENS REQUIÃO, o dever de informar "é o dever de revelar certas situações e negócios em que a companhia e os administradores estão empenhados, e que podem influir no mercado, no que se refere aos valores mobiliários por ela emitidos. A disclosure constitui, pois, um conjunto de regras que visam a proteger a lisura e a respeitabilidade do mercado de capitais. Não se refere propriamente à informação sobre os negócios inerentes à realização do objeto social da companhia, pois esses integram e são protegidos pelos princípios do sigilo profissional da empresa, mas diz respeito a tudo aquilo que possa influir na cotação dos valores mobiliários (ações, debêntures) emitidos pela companhia, e que são objeto de operações do mercado" (REQUIÃO, 1995: 172).

No que tange ao primeiro aspecto do dever de informação para os acionistas, tem-se que este se consubstancia no momento da posse do administrador que deverá declarar aos acionistas a existência em seu patrimônio de ações, bônus de subscrição, opções de compra de ações e debêntures conversíveis em ações, que sejam de emissão da companhia, sociedades controladas ou outras empresas do mesmo grupo (art. 157, § $1^{\circ}$, LSA), bem como que tais informações e outras de caráter burocrático e negocial sejam prestadas em sede de assembléia-geral ordinária quando a pedido de acionistas que representem $5 \%$ (cinco por cento) ou mais do capital social da companhia.

Tais informações de cunho pessoal do administrador repercutem no problema de conflito de interesses entre os administradores e a companhia, cuidando-se de remédio preventivo de transações perniciosas e desonestas, bem como esclarecedor, caso subsistam dúvidas.

Relativamente ao segundo aspecto do dever de informar, cuidando-se das informações prestadas ao mercado de modo geral e, especificamente, à Comissão de 
Valores Mobiliários (CVM) - órgão fiscalizador e regulador do mercado de capitais a relevância do dever de informar torna-se ainda mais pungente, pois é com base em tais informações que o mercado de capitais conhece e torna-se apto a julgar a qualidade do investimento que a empresa representa.

Dessa feita, o dever de informar interfere nas posições do mercado de capitais aumentando ou diminuindo sua rapidez e eficiência, bem como seus lucros e perdas, funcionando não só como termômetro do volume de negociações, mas também de norte e proteção aos investidores, especialmente os de menor porte.

\section{A RESPONSABILIDADE CIVIL DO ADMINISTRADOR NA LSA}

Várias são as correntes doutrinárias no sentido de atribuição de responsabilidade do administrador, desde aquelas que entendem que a pessoa jurídica não responde pelos atos de seus administradores, haja vista que consistem em ficção jurídica e carecem de vontade, sendo tal teoria defendida por SAVIGNY, passando àquelas que defendem a responsabilidade integral dos administradores fundadas na justiça e eqüidade.

Mais acertadas, porém, são as teorias realistas que defendem a ampla responsabilidade da pessoa jurídica, que se encontra comprometida desde que concorram os seguintes requisitos: a) haja culpa do administrador exceto quando o fundamento da responsabilidade for objetivo, e b) o administrador deve ter diretamente contribuído ao evento danoso dentro da esfera da pessoa jurídica no exercício de suas funções ou atribuições (ALSINA, 1986: 422).

No Brasil, os diretores e conselheiros das sociedades anônimas não se vinculam solidariamente pelos atos normais de administração social que praticarem, haja vista serem órgãos da pessoa jurídica, sendo que, nessa condição, agem em nome e em conta da sociedade que representam e comandam.

Tal situação é a aplicação do princípio da irresponsabilidade dos administradores e se justifica, pois a sociedade é pessoa jurídica que não se confunde com a pessoa física que a representa (salvo nos casos excepcionais de aplicação da teoria da desconsideração da personalidade jurídica não abrangidos pelo presente estudo), fazendo coro, ainda, com o princípio da total autonomia da personalidade jurídica da sociedade em relação à pessoa de seus administradores conforme prescrito nos arts. 17 e 20 do Código Civil.

Ora, o ato é da pessoa jurídica, não do seu gestor-representante, daí a presunção juris tantum de que $\mathrm{o}$ ato fora praticado dentro dos poderes cabentes ao administrador, em concordância com a lei ou com os atos constitutivos da empresa, ou seja, exercidos no âmbito regular de gestão empresarial, a fim de que o administrador não seja individualmente responsabilizado, porque tão-somente externa a vontade da sociedade.

A situação de inatingibilidade dos administradores, entretanto, rui ao trespassarem os atos ordinários de gestão administrativa, ou, ainda, quando, atuando no exercício regular de suas funções, agirem com culpa ou dolo, infringindo os deveres legalmente atribuídos ou previstos nos estatutos sociais, acarretando assim a obrigação pessoal de reparar os danos gerados à sociedade, aos sócios e a terceiros. 
Ora, o direito societário brasileiro incorporou ao seu sistema de responsabilidade do administrador as regras do direito civil, que, por sua vez, se pautaram pela linha de pensamento implantada pelos jurisconsultos da época clássica, abrigando a tradição do direito romano ao adotar duas formas distintas de se imputar a responsabilidade civil, quais sejam, a decorrente de contrato - responsabilidade contratual - e a responsabilidade por ato delitual (ato ilícito) - responsabilidade extracontratual presente respectivamente nos arts. 1.056 e 159 do Código Civil.

Ressalte-se, contudo, que a responsabilidade patrimonial do administrador de sociedade anônima não tem índole contratual, situando-se na esfera da responsabilidade extracontratual ou aquiliana, presente no art. 159 do Código Civil no qual "aquele que, por ação ou omissão voluntária, negligência, ou imprudência, violar direito, ou causar prejuízo a outrem, fica obrigado a reparar o dano" se espraiando pelo ordenamento jurídico vindo a ser uma das fontes informadoras de responsabilidade no campo do direito societário.

Com efeito, dispõe a LSA que o administrador da sociedade anônima não é pessoalmente responsável pelas obrigações que contrair em nome da sociedade quando se tratar de ato regular de gestão (art. 158, caput), mas que responderá civilmente pelos prejuízos que causar com culpa ou dolo dentro de suas atribuições (art. 158, inciso I), ou quando agir violando dispositivo de lei ou do estatuto (art. 158, inciso II).

Para FÁBIO ULHOA COELHO, não há distinção entre os sistemas de responsabilidade civil constantes dos incisos I e II do art. 158 da LSA, pois ambas as hipóteses são interdefiníveis e consagram a responsabilidade civil do tipo clássico, e o fundamento para atribuir ao administrador a obrigação de ressarcir os danos gerados por sua conduta será sempre o descumprimento de um dever legal (COELHO, 2001: 257).

FRAN MARTINS, MODESTO CARVALHOSA e NILTON LATORRACA, por sua vez, entendem que a hipótese trazida no inciso I cuida de responsabilidade subjetiva do tipo clássico, cujo elemento é o agir dentro de suas atribuições e poderes com culpa ou dolo, porém, no que tange ao inciso II, sustentam os doutrinadores tratar-se de responsabilidade objetiva, fundados em que a responsabilidade independe de conduta culposa ou dolosa, bastando infração ao estatuto ou à lei (MARTINS, 1988: p. 157; CARVALHOSA e LATORRACA, 1997: 317).

A matéria ganha destaque ao vislumbrarmos a existência de duas relações distintas, uma estabelecida entre o administrador e a companhia, bem como entre o administrador e os acionistas desta (interna corporis), e outra, entre o administrador e terceiros (externa corporis), gerando conseqüências diversas no campo da responsabilidade, especialmente no campo probatório.

Assim, verificado o evento danoso e os demais elementos ensejadores da responsabilidade, cumpre verificar-se de que tipo de relação está a se tratar, ou seja, se de relação interna corporis ou de relação externa corporis, para se vislumbrar ou não a possibilidade de se dilargar a culpa imputada ao administrador. 
Com efeito, para as relações internas da empresa, a responsabilidade patrimonial do administrador tem caráter subjetivo, filiando-se ao sistema clássico do Código Civil, restando imprescindível ao lesado - sociedade e/ou sócios - a prova de que o administrador agiu com culpa ou dolo, levando-se em conta a preciosidade da atividade administrativa.

A aplicação da teoria da responsabilidade subjetiva clássica para a atividade do administrador nas relações internas da empresa faz-se imperiosa sob pena de cometermos injusto insanável. Isso porque o administrador não concentra poderes de ordem absoluta, pelo contrário, sempre limitados por lei ou por convenção estatutária.

Vale dizer, o administrador não age aleatoriamente, tampouco sozinho, aliás, cada vez mais ganham aplicabilidade as formas de administração colegiada, de caráter eminentemente profissional, pautando suas decisões em relatórios, balanços, estudos de mercado e uma variedade de informações técnicas que conduzem a uma determinada deliberação coletiva.

Daí a necessidade de se delimitar a extensão da responsabilidade do administrador quando em sua relação com a companhia e os acionistas, sendo mister que, para se imputar o dever de reparação, se fixe o grau de culpabilidade e envolvimento do mesmo na lesão, especialmente se há outros administradores envolvidos, a fim de se determinar também os limites da solidariedade na obrigação.

Assim, exsurge a responsabilidade subjetiva tanto quando o administrador agir dentro de suas atribuições ou poderes com culpa ou dolo, ou quando agir em infração à lei ou ao estatuto social, nesse ponto assistindo razão a FÁBIO ULHOA COELHO ao afirmar que ambos os incisos são interdefiníveis, já que qualquer ato danoso seja ele com culpa ou dolo, fatalmente estará em contraposição à regra legal ou estatutária.

Nesse diapasão, temos que a LSA não abriga o sistema de responsabilidade objetiva, vez que esta apenas pode ser atribuída por expressa determinação legal, por exemplo, como ocorre no Código de Defesa do Consumidor (Lei n ${ }^{\circ} 8.078$, de 11 de setembro de 1990), ou na Lei de Crimes Ambientais (Lei $n^{\circ}$ 9.605, de 12 fevereiro de 1998).

Ademais, se o administrador inescrupuloso ou inabilidoso agiu provocando dano a sociedade ou aos seus sócios, é de se salientar, ainda, a falta de fiscalização adequada do restante do corpo social, ou seja, o corpo administrativo - outros gerentes, diretores e executivos -, especialmente dos sócios que falharam no dever de acompanhar a vida social, o que corrobora na aplicação da responsabilidade subjetiva do tipo clássico, cabendo à companhia ou aos acionistas a prova de que os atos lesivos do administrador foram praticados à revelia de suas vontades e fiscalização.

Nesse sentido FÁBIO ULHOA COELHO coloca interessante exemplo no qual o presidente de uma multinacional apostou no investimento em determinado produto que as pesquisas de marketing indicavam como de baixa repercussão, mas que, ao final em sentido contrário ao esperado, gerou lucros extraordinários. Nesse exemplo, se tivesse havido prejuízo como apontado pelos estudos técnicos, restaria configurada a 
responsabilidade do administrador isoladamente para com a empresa (COELHO, 2001: 256).

Já tivemos a oportunidade de ressaltar o fato de que raramente o administrador age sozinho e, em que pese os poderes e liberdades inerentes ao cargo exercido, não há liberdade absoluta. Tanto é assim, que são cada vez mais escassas as empresas que mantêm engessado e centralizado o cargo administrativo, que cedem espaço a órgãos administrativos com múltiplas e específicas funções, que contribuem ativa e constantemente em toda e qualquer deliberação da companhia, especialmente naquelas que importem risco negocial. Daí ser imprescindível a delimitação da exata extensão da participação do administrador nas condutas reputadas como infratoras da lei ou do estatuto.

Assim sendo, no tocante às relações internas da companhia, a responsabilidade do administrador é do tipo subjetivo, vez que não há na LSA previsão de ocorrência de responsabilidade objetiva específica, capaz de afastar a responsabilidade subjetiva do tipo clássico, mormente considerando-se a interdependência dos incisos do art. 158, bem como pela interpretação sistemática da matéria que conduz à aplicação da regra geral.

Relativamente às relações externas da esfera social, resta coerente que se mantenha o sistema de responsabilidade subjetiva, porém com a inversão do ônus probatório, ou seja, que haja presunção de culpa, e que esta fique a ser desconstituída pelo acusado. Tal pensamento decorre da necessidade de se preservar o terceiro de boa-fé que não tem como se imiscuir nos negócios sociais e não poderá arcar com os prejuízos causados pela sociedade em virtude de ação ou omissão de seu administrador.

Ora, se aos membros da companhia incumbe o poder e o dever legal de escolher seus administradores, subsistindo ainda a obrigação de fiscalizá-los, tais faculdades não se permitem a terceiros, que sofrerão imensa dificuldade em adentrar nos papéis e documentos sociais, bem como em comprovar a intenção da psique do administrador a fim de ter seu prejuízo reparado. Diante de tal quadro, não podendo o direito pactuar com o injusto, deve prevalecer o princípio da boa-fé em benefício do terceiro lesado.

É nesse sentido a precisa e pertinente lição de JOSÉ DE AGUIAR DIAS:

"Se é relativamente fácil provar o prejuízo, já o mesmo não acontece com a demonstração da culpa. A vítima tem à sua disposição todos os meios de prova, pois não há, em relação à matéria, limitação alguma. Se, porém, fosse obrigada a provar, sempre e sempre, a culpa do responsável, raramente seria bem sucedida na sua pretensão de obter ressarcimento. Os autores mais intransigentes na manutenção da doutrina subjetiva reconhecem o fato e, sem abandonar a teoria da culpa, são unânimes na admissão do recurso à inversão da prova, como fórmula de assegurar ao autor as probabilidades de bom êxito que de outra forma lhe fugiriam totalmente em muitos casos. Daí decorrem as presunções de culpa e de causalidade estabelecidas em favor da vítima: com esse caráter só pela vítima podem ser invocados."

E acrescenta, mais adiante: 
"Assim, o princípio de que ao autor incumbe a prova não é derrogado em matéria de responsabilidade civil, mas recebe nesse domínio, em lugar do seu aparente sentido absoluto, uma significação especial, que por atenção a outra norma (reus in excipiendo fit actor) vem a ser esta: 'aquele que alega um fato contrário à situação adquirida do adversário é obrigado a estabelecer-lhe a realidade'. Ora, quando a situação normal, adquirida, é a ausência de culpa, o autor não pode escapar à obrigação de provar toda vez que, fundamentadamente, consiga o réu invocá-la. Mas, se, ao contrário, pelas circunstâncias peculiares à causa, outra é a situação modelo, isto é, se a situação normal faça crer na culpa do réu, já aqui se invertem os papéis: é ao responsável que incumbe mostrar que, contra essa aparência, que faz surgir a presunção em favor da vítima, não ocorreu culpa de sua parte" (DIAS, 1997: 91).

Claro está que tal caso sucumbe à hipótese de conluio entre administrador e terceiro para conjuntamente lesarem a sociedade, nesse caso havendo direito de reparação para a companhia lesada apuradas as respectivas atuações.

Verifica-se, assim, que, ao se tratar de relação externa corporis, o tratamento para fins de responsabilidade é distinto das relações interna corporis; enquanto, nas relações interna corporis, cabe à sociedade e/ou aos sócios o ônus probatório de que houve culpa ou dolo do administrador, tratando-se de responsabilidade subjetiva do tipo clássico, nas relações externa corporis, ocorre inversão do ônus probandi em proteção ao terceiro prejudicado, aparecendo a figura da responsabilidade subjetiva com presunção de culpa.

Com efeito, no que tange à delimitação da responsabilidade do administrador, urge adotarmos um caminho do meio, ou seja, uma teoria de equilíbrio de responsabilidades entre administrador e sociedade. Se, de um lado, aquele que sofreu lesão decorrente de má gestão empresarial, seja por qual razão tenha ocorrido, não pode ficar a mercê de se achar ou não culpados para receber seu ressarcimento; de outro, não se pode olvidar a injustiça que seria ampliar ostensivamente a responsabilidade individual do administrador que atende a uma gama de interesses da companhia, acerca dos atos praticados em nome da pessoa jurídica sem adentrarmos no grau de culpabilidade e envolvimento que tenha concorrido na feitura do dano.

A necessidade de se equacionar responsabilidades distanciando-se da responsabilidade individual do administrador, para uma contemporização na qual figurem administrador (pessoa física) e sociedade (pessoa jurídica), afasta a possibilidade de excessos interpretativos da lei que podem em grande escala comprometer a própria evolução econômica, vez que, ao onerar demais o administrador e comprometer patrimônios pessoais, pode gerar desmotivação na escalada por novos empreendimentos imprescindíveis para se atingir a finalidade última da empresa que é promover desenvolvimento econômico visando ao bem-estar social.

\section{CONCLUSÃO}

A responsabilidade dos administradores de sociedades anônimas ainda é assunto dos mais polêmicos, especialmente em face da omissão e falta de acuidade legislativa. 
Diversas são as soluções que a doutrina vem propondo a fim de se estabelecerem regras mais precisas para aferição da responsabilidade dos gestores sociais, das mais simplistas e menos rigorosas àquelas que pecam pelos excessos interpretativos, ambas comprometendo não só a necessidade de se perfazer justiça, como também de se equilibrar relações.

Falamos que o direito comercial tem raízes consuetudinárias e que tendem ao não formalismo. Contudo, tal característica não pode servir de máscara para administradores inescrupulosos e que façam mau uso da autonomia da pessoa jurídica. De outro lado, os negócios comerciais de índole econômica, sofrendo inúmeras transformações face especialmente ao crescimento da tecnologia, à velocidade de informações e alterações, oferecem riscos cada vez maiores que operam mudanças nas estruturas sociais e modificam relações especialmente no universo societário.

Diante de tal situação, o sistema da responsabilidade subjetiva clássica nem sempre atende com suficiência os anseios de justiça clamados pelo ressarcimento de danos, carecendo especialmente no trato com terceiros, seja qual for o tipo de relação com eles estabelecidas, meio mais eficaz para atingir o seu fim último que é a reparação do mal feito, sem depender de casuísmos.

Daí a defesa de um caminho central, que situe a responsabilidade entre administrador e companhia em ponto de equilíbrio. Esse equilíbrio que protege os terceiros de boa-fé também impede que o administrador faça uso ilícito de sua posição e dos privilégios que ela lhe confere, bem como que por outra via seja massacrado pela pessoa jurídica e sua estrutura.

Assim, a divisão das relações sociais, mormente pelos efeitos e conseqüências, no âmbito interno e no externo, se mostra como o modo de se atingir o preconizado equilíbrio, distribuindo-se forças e deveres, repartindo-se responsabilidades sem injustiças e atendendo as necessidades do quadro histórico econômico e social atual.

\section{REFERÊNCIAS BIBLIOGRÁFICAS}

ABRÃO, Nelson. Sociedade por quotas de responsabilidade limitada. 8. ed. São Paulo: Saraiva, 2000

ALSINA, Jorge Bustamante. Teoría general de la responsabilidad civil. 5. ed. Buenos Aires: Abeledo-Perrot, 1986.

ASCARELLI, Tullio. Sociedades y asociaciones comerciales. Buenos Aires: Ediar, 1947.

BIANCA, Massimo C. Diritto civile. IV - Obligazione. Milano: Dott. A. Giuffrè Editore, 1990. BORBA, José Edwaldo Tavares. Direito societário. 5. ed. Rio de Janeiro: Renovar, 1999.

CARVALHOSA, Modesto; LATORRACA, Nilton. Comentários à lei de sociedades anônimas. São Paulo: Saraiva, v. 3, 1997.

COELHO, Fábio Ulhoa. Curso de direito comercial. 4. ed. São Paulo: Saraiva, v. 2, 2001.

DIAS, José de Aguiar. Da responsabilidade civil. 10. ed. 3. tiragem. Rio de Janeiro: Forense, v. I, 1997.

GALGANO, Francesco. Trattato di diritto comerciale e di diritto pubblico delle'economia - la societá per azioni. 2. ed. Itália: Ceda-Padova, v. 7, 1988. 
HAMEL, J.; LAGARDE, G.; JAUFFRET. A. Societés, groupments d'intérêt économique, entreprises publiques. 2. ed. [s.1.]: Dalloz, t. 1, v. 2, 1980.

LORENZETTI, Ricardo Luis. Derecho de daños. Buenos Aires: La Rocca, 1993.

LUCENA, Jose Waldecy. Das sociedades por cotas de responsabilidade limitada. 2. ed. Rio de Janeiro: Renovar, 1997.

MARTINS, Fran. Novos estudos de direito societário. São Paulo: Saraiva, 1988.

MONTENEGRO, Antonio Lindbergh C. Responsabilidade civil. 2. ed. Rio de Janeiro: Lumen Juris, 1996.

MOSQUERA, Roberto Quiroga (coord.). Aspectos atuais do direito do mercado financeiro. São Paulo: Dialética, 1999.

PAES, Paulo Roberto Tavares. Responsabilidade dos administradores de sociedades. São Paulo: RT, 1978.

REQUIÃO, Rubens. Curso de direito comercial. 20. ed. São Paulo: Saraiva, v. 2, 1995.

RIPERT, Georges; ROBLOT, René. Traité de droit commercial. 13. ed. Paris: LGDJ, t. 1, 1989.

SUCH, Jose Maria Garreta. La responsabilidade civil, fiscal y penal de los administradores de las sociedades. Madri: Marcial Pons, 1991. 